\title{
Characterization of a Regular Array in the Wall of Lactobacillus buchneri and its Reattachment to the Other Wall Components
}

\author{
By KUNIYOSHI MASUDA AND TOMIO KAWATA* \\ Department of Food Microbiology, Tokushima University School of Medicine, \\ Tokushima 770, Japan
}

(Received 4 August 1980; revised 4 November 1980)

\begin{abstract}
A regular array exhibiting hexagonal periodicity with a centre-to-centre spacing of about $6 \mathrm{~nm}$ was found on the wall surface of freeze-etched Lactobacillus buchneri. The regular array was composed of a subunit protein with a molecular weight of about 55000 as determined by sodium dodecyl sulphate-polyacrylamide gel electrophoresis. Subunits isolated from the wall by extraction with guanidine hydrochloride reassembled into the original regular array after dialysis against distilled water. The subunits could reattach to wall fragments from which most of the teichoic acid had been extracted with cold trichloroacetic acid, but not to wall fragments from which most of the neutral polysaccharide had been removed by treatment with hot formamide. Heterologous reattachment of the subunits took place on to Lactobacillus casei subsp. casei wall fragments which had been partially hydrolysed under mild acid conditions. These observations suggest that the subunit protein binds to a neutral polysaccharide moiety in the underlying wall layer but not to peptidoglycan or teichoic acid.
\end{abstract}

\section{INTRODUCTION}

Regular arrays composed of hexagonally or tetragonally arranged protein subunits are present on the wall surface of various bacteria (Glauert \& Thornley, 1969). Under certain conditions, isolated subunits from a variety of bacteria possess the ability to reattach to the supporting layer from which they have been removed (homologous reattachment) or to that of another organism (heterologous reattachment) (Sleytr, 1975, 1978). However, there have been few studies on the interaction between the subunits and the underlying wall components. In Gram-negative bacteria, the subunit proteins of Acinetobacter sp. (Thorne et al., 1975) and Spirillum serpens (Chester \& Murray, 1978) were shown to be bound to an outer membrane protein and to a lipid-lipopolysaccharide complex, respectively. On the other hand, in Gram-positive bacteria, the subunit protein of Bacillus sphaericus was considered to be associated with the peptidoglycan sacculus (Hastie \& Brinton, $1979 \mathrm{~b}$ ).

We reported the presence of tetragonal arrays in the outer wall layer of Lactobacillus fermentum (Kawata et al., 1974) and Lactobacillus brevis (Masuda \& Kawata, 1979). Furthermore, we achieved the reattachment of the subunits of $L$. brevis into a regular array on wall fragments of this organism (Masuda \& Kawata, 1980). In the present study, we have observed a regular array composed of protein subunits on the wall of Lactobacillus buchneri and have examined its morphological and chemical properties. To examine the nature of the binding of the subunit protein to the other wall component(s), we have investigated the reattachment of the isolated subunits to wall fragments treated in various ways. It is suggested that the subunit protein links to a neutral polysaccharide moiety in the underlying wall layer. 


\section{METHODS}

Organisms and growth. Lactobacillus buchneri ATCC 4005 and L. casei subsp. casei ATCC 393 were obtained from the Yakult Institute, Tokyo, Japan. Cells were grown at $37^{\circ} \mathrm{C}$ in the liquid medium of Efthymiou \& Hansen (1962) as described previously (Kawata et al., 1974), and harvested from a $12 \mathrm{~h}$ culture in the late-exponential phase.

Preparation of walls. Washed cells were disrupted in a Braun MSK cell homogenizer by shaking with glass beads for $50 \mathrm{~s}$, and wall fragments were then isolated by differential centrifugation after treatment with $2 \%(\mathrm{v} / \mathrm{v})$ Triton X-100 as described previously (Masuda \& Kawata, 1979). The fragments were treated for $2 \mathrm{~h}$ at $37^{\circ} \mathrm{C}$ with deoxyribonuclease I (Worthington Biochemical Co.) and ribonuclease A (Sigma), at concentrations of 2 and $10 \mu \mathrm{g} \mathrm{ml}{ }^{-1}$ respectively, in $50 \mathrm{mM}$-Tris/ $\mathrm{HCl}$ buffer ( $\mathrm{pH} \mathrm{7.2)} \mathrm{containing} 2 \mathrm{mM}-\mathrm{MgCl}_{2}$. The samples were then washed three times with distilled water and recentrifuged. The pellet obtained was used as the wall fraction.

Isolation of a regularly arranged layer from walls. The wall fraction of $L$. buchneri was treated with lysozyme to remove the underlying peptidoglycan layer and fragments of the regularly arranged layer were isolated as described previously (Masuda \& Kawata, 1979).

Isolation of regularly arranged subunits and preparation of wall fragments free of the subunits. The regularly arranged subunits were isolated from the wall fraction of $L$. buchneri by extraction with 4 M-guanidine hydrochloride $(\mathrm{GHCl})$ as described previously (Masuda \& Kawata, 1980). The resulting fraction of wall fragments free of the subunits is referred to as $\mathrm{GHCl}$-wall.

Extraction of wall components. The GHCl-wall was treated twice with $1 \%(\mathrm{w} / \mathrm{v})$ sodium dodecyl sulphate (SDS) at $100^{\circ} \mathrm{C}$ for $30 \mathrm{~min}$ and washed three times with distilled water followed by centrifugation. The resulting pellet is termed SDS-wall. The SDS-wall was then extracted either twice with $10 \%(\mathrm{w} / \mathrm{v})$ trichloroacetic acid (TCA) at about $4{ }^{\circ} \mathrm{C}$ for $18 \mathrm{~h}$ or five times with formamide at $150^{\circ} \mathrm{C}$ for $1 \mathrm{~h}$, and was then washed three times with distilled water followed by centrifugation. These fractions are referred to as TCA-wall and formamide-wall respectively. In addition, the SDS-wall from $L$. casei subsp. casei was partially hydrolysed in $0.5 \mathrm{M}-\mathrm{HCl}$ at $60^{\circ} \mathrm{C}$ for $30 \mathrm{~min}$ and then washed three times with distilled water. The wall thus hydrolysed is called $\mathrm{HCl}$-wall.

Reassembly of isolated subunits and their reattachment to wall fragments. For reassembly or reattachment, the subunits isolated by $\mathrm{GHCl}$ extraction, or mixtures of the isolated subunits and the wall fractions which had been subjected to various extraction procedures, were dialysed against distilled water to remove GHCl. The excess of subunits over the wall fractions in the mixtures was approximately three times that of the intact wall.

$S D S$-polyacrylamide gel electrophoresis. The reassembled product (about $10 \mu \mathrm{g}$ ) obtained from the isolated subunits as described above was subjected to SDS-polyacrylamide slab gel electrophoresis according to Laemmli (1970), using a separating gel of $12 \%(w / v)$ acrylamide. The gel was fixed, stained with Coomassie brilliant blue and destained to detect protein as described by Fairbanks et al. (1971). Molecular weight marker proteins were bovine serum albumin, chymotrypsinogen from bovine pancreas (Sigma), ovalbumin (ICN Pharmaceuticals), alcohol dehydrogenase from yeast and phosphorylase $a$ from rabbit muscle (Boehringer Mannheim). Glycoprotein was detected by the periodate-Schiff method according to Zacharius et al. (1969).

Chemical analyses. Protein, neutral sugar and phosphorus were determined by the methods of Lowry, Dubois $e t$ al. (1956) and Allen (1940), respectively. Amino sugar was assayed by the method of Rondle \& Morgan (1955) after hydrolysis of the wall fractions in $4 \mathrm{M}-\mathrm{HCl}$ at $100^{\circ} \mathrm{C}$ for $8 \mathrm{~h}$. Glycerol and ribitol were detected by thin-layer chromatography after hydrolysis of the SDS-wall in $4 \mathrm{M}-\mathrm{HCl}$ at $100^{\circ} \mathrm{C}$ for $12 \mathrm{~h}$ according to the method of Matsuno \& Slade (1970), as described previously (Masuda \& Kawata, 1980). Amino acids were analysed on a Yanaco LC-5S amino acid analyser (Yanagimoto Co., Tokyo) after hydrolysis of the formamide-wall in $6 \mathrm{M}-\mathrm{HCl}$ at $100{ }^{\circ} \mathrm{C}$ for $8 \mathrm{~h}$.

Electron microscopy. Freeze-etching was performed in a Hitachi HFZ-1 freeze replica apparatus equipped with an etching unit type FE-1 as described previously (Kawata et al., 1974). Negative staining was carried out with $2 \%(\mathrm{w} / \mathrm{v})$ ammonium molybdate in $0.1 \mathrm{M}$-ammonium acetate buffer $(\mathrm{pH} 7.0)$ or $1 \%(\mathrm{w} / \mathrm{v})$ uranyl acetate (pH 4.1). Specimens were examined with a Hitachi HU-11E electron microscope operating at 75 or $100 \mathrm{kV}$.

Optical diffraction. Electron microscopic images were reversed on to photographic films by contact printing. Optical diffraction was performed on selected areas of the reversed images with an Eiko LD-10 optical diffractometer (Eiko Engineering Co., Tokai-mura, Ibaraki, Japan).

\section{RESULTS}

\section{Structure of regular array}

Figure $1(a)$ shows a freeze-etched whole cell of $L$. buchneri. The outer surface of the wall was covered with a regular array of subunits. The centre-to-centre spacing of the globular subunits in the regular array was about $6 \mathrm{~nm}$, and optical diffraction (Fig. $1 a$, inset) revealed that the subunits were arranged hexagonally. Negatively stained preparations of the wall 

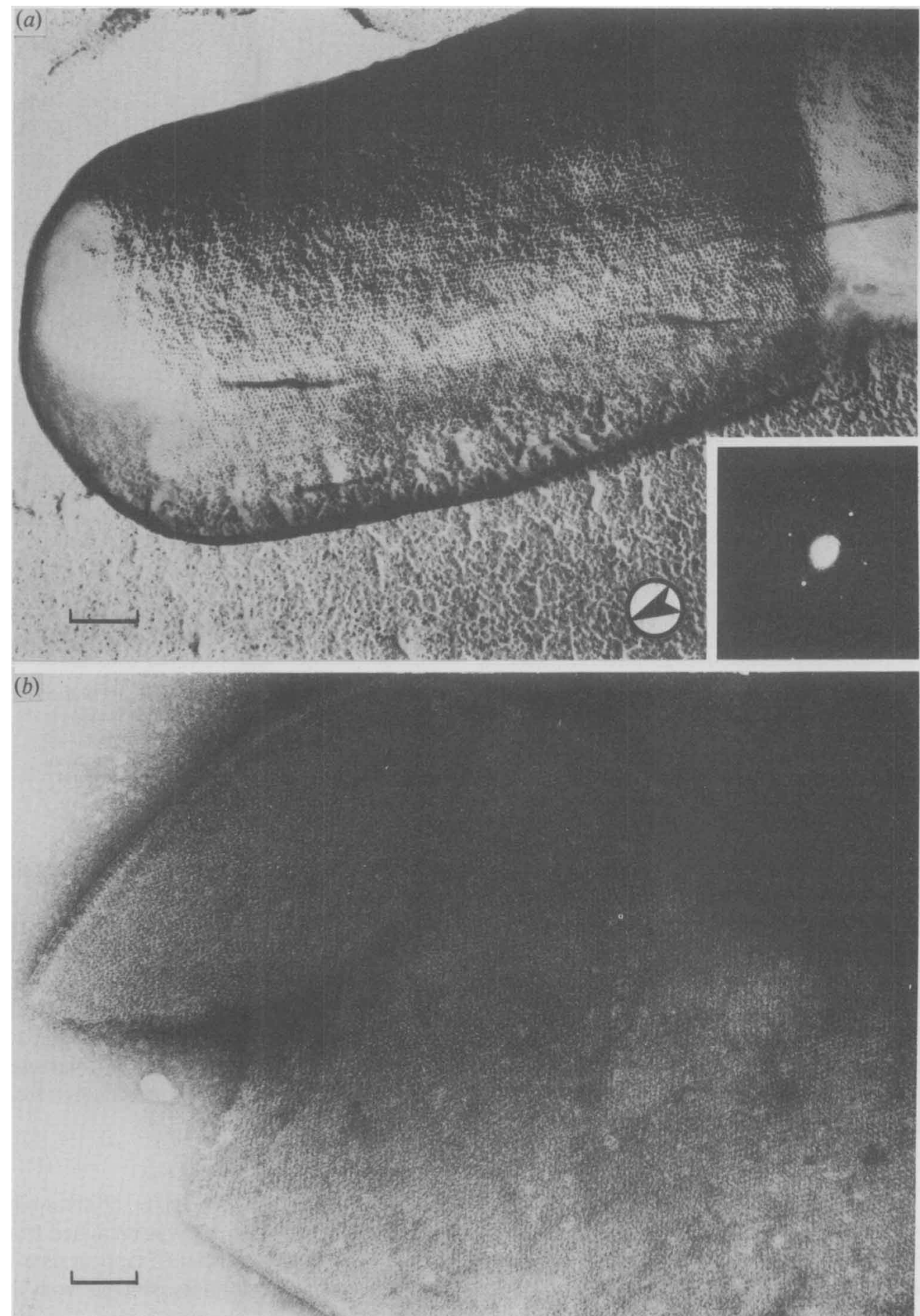

Fig. 1. (a) Freeze-etched cell of L. buchneri. The direction of shadowing is indicated by the encircled arrow. Shadows appear as bright contrast, since the micrograph was not printed in reverse. The cell surface is covered with a regular array composed of hexagonally arranged subunits. The inset shows an optical diffraction pattern from a selected area of the micrograph, displaying a hexagonal periodicity. (b) Isolated wall from $L$. buchneri. Regular patterns are seen on the wall. Negatively stained with ammonium molybdate. The bar markers represent $100 \mathrm{~nm}$. 

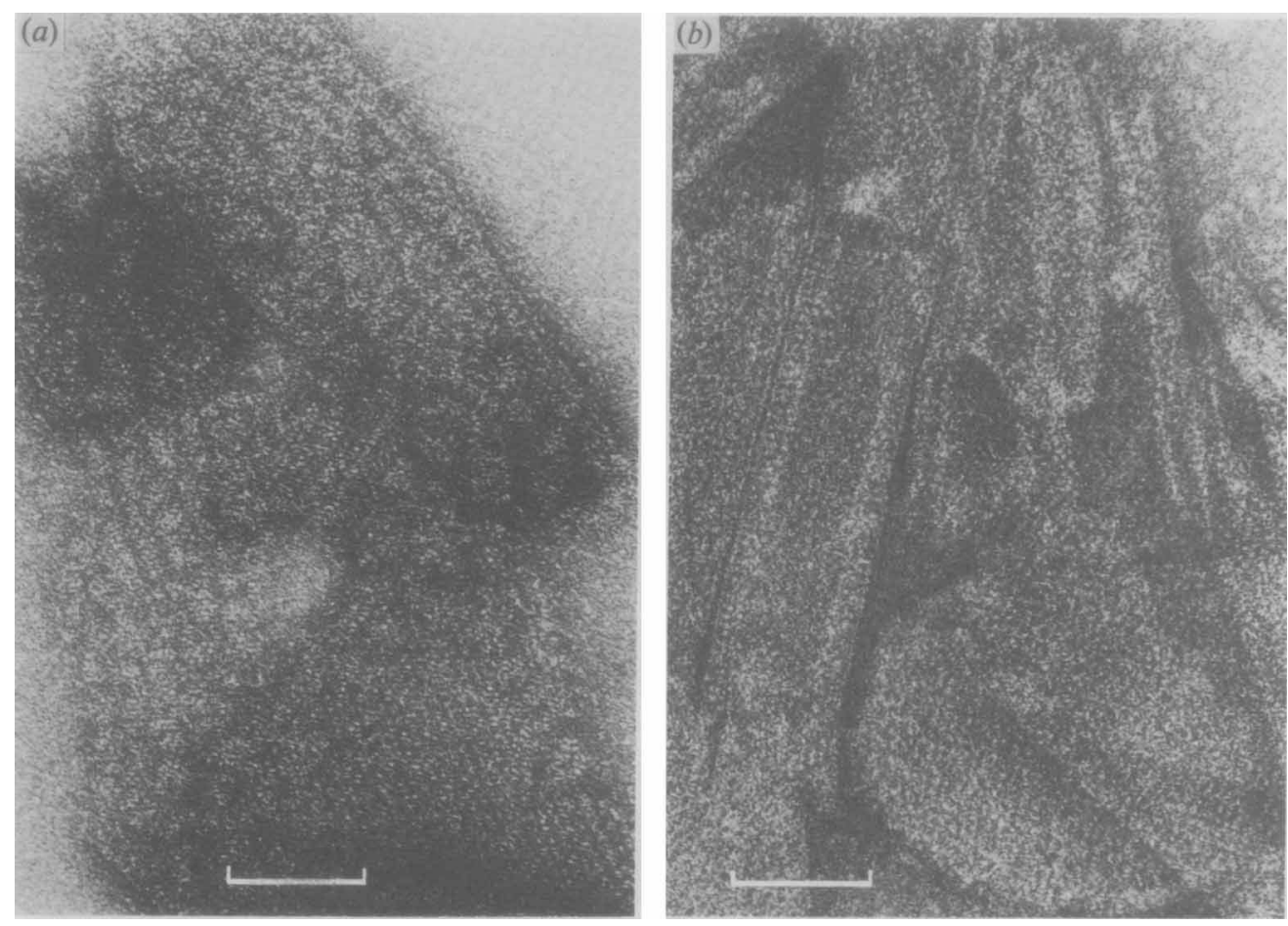

Fig. 2. (a) Fragments of the regularly arranged layer isolated from the wall fraction of L. buchneri after treatment with lysozyme. The subunits are seen as white dots arranged in a striated pattern. Negatively stained with uranyl acetate. (b) Reassembled products obtained by dialysing the isolated subunits from $L$. buchneri wall against distilled water. The subunits have reassembled into cylinders and flat sheets of various sizes. Negatively stained with ammonium molybdate. The bar markers represent $100 \mathrm{~nm}$.

fraction obtained from mechanically disrupted cells showed that the wall also had a regular array which appeared to be hexagonally arranged (Fig. $1 b$ ). However, it was difficult to resolve the fine structure and arrangement of the subunits because of the presence of the underlying wall layer.

The wall fraction was treated with lysozyme to digest the underlying peptidoglycan layer. Figure 2(a) shows negatively stained fragments of the regularly arranged layer obtained after digestion with lysozyme. The regular array was seen as striations running along the surface and was composed of the subunits, visible as white dots about $2 \mathrm{~nm}$ in diameter. Unfortunately, no useful information on the arrangement of the subunits was obtained from the electron micrograph, possibly due to distortion during sampling.

\section{Detachment and reassembly of regularly arranged subunits}

When isolated walls from $L$. buchneri were treated with the hydrogen bond-disrupting agent $\mathrm{GHCl}$ at a concentration of $4 \mathrm{M}$ for $2 \mathrm{~h}$ at $37^{\circ} \mathrm{C}$, the regular array was detached from the walls, exposing the underlying layer, which had a smooth bag-shaped appearance in negatively stained preparations (Fig. $4 a$ ). The regularly arranged subunits isolated from the wall fraction by extraction with $\mathrm{GHCl}$ were examined by electron microscopy for their capacity to re-form the regular pattern upon removal of GHCl. As shown in Fig. $2(b)$, the subunits reassembled into flat sheets and cylinders of various sizes. Added ions were not necessary for this reassembly of the subunits. On the basis of these observations it is assumed that the subunits are bound to each other by hydrogen bonds but not by ionic bonds, including divalent cation bridges, or by covalent bonds. 


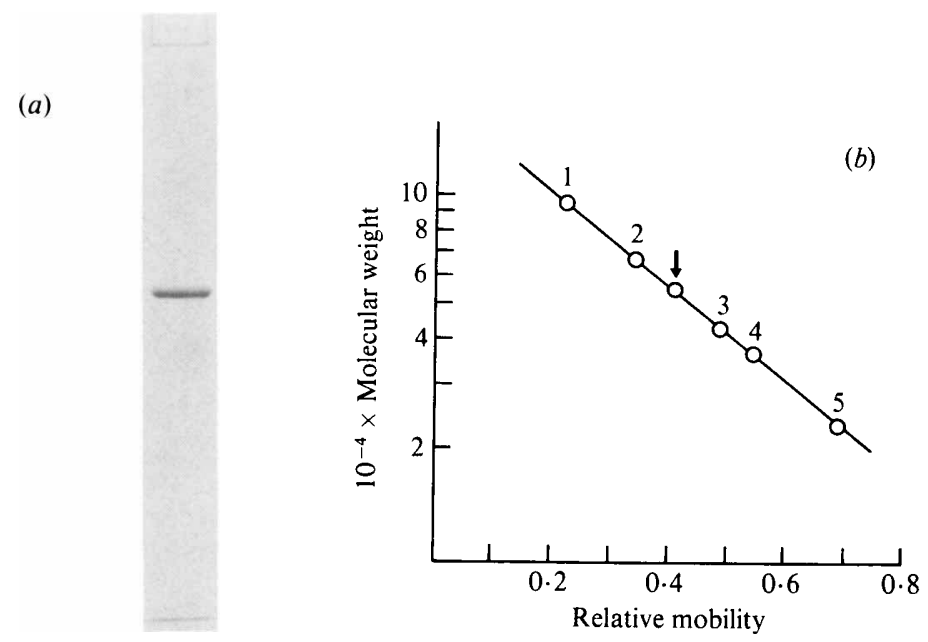

Fig. 3. (a) SDS--polyacrylamide gel electrophoresis of the reassembled product from the isolated subunits of L. buchneri. (b) Molecular weight determination of the subunit protein (arrowed symbol). The marker proteins used were (1) phosphorylase $a$, (2) bovine serum albumin, (3) ovalbumin, (4) alcohol dehydrogenase and (5) chymotrypsinogen.

\section{$S D S$-polyacrylamide gel electrophoresis of the subunit protein}

The reassembled product from isolated subunits of the regular array of L. buchneri contained approximately $96.5 \%(\mathrm{w} / \mathrm{w})$ protein when the freeze-dried preparation was analysed. SDS-polyacrylamide gel electrophoresis revealed one main protein band and a few very faint bands (Fig. $3 a$ ). The main band is believed to be the subunit protein of the regular array. The apparent molecular weight of this protein was estimated to be about 55000 by comparison with marker proteins (Fig. $3 b$ ). No staining was seen with periodate-Schiff reagent, indicating the absence of detectable glycoprotein.

\section{Reattachment of isolated subunits to homologous wall fragments}

When the subunits isolated from walls by $\mathrm{GHCl}$ extraction were mixed with subunit-free fragments of $\mathrm{GHCl}$-wall or SDS-wall and the mixture was dialysed against distilled water, the subunits reattached to the wall fragments, re-forming into irregularly oriented patches of pattern (Fig. $4 b, c$ ). No specific cations were required for the reattachment, since this could be achieved simply by the removal of $\mathrm{GHCl}$ by dialysis.

The main components of the L. buchneri wall are peptidoglycan, composed of muramic acid, glucosamine, alanine, glutamic acid, lysine and aspartic acid (Kandler, 1970), glycerol teichoic acid (Shaw \& Baddiley, 1964) and neutral polysaccharide containing glucose and galactose (Shimohashi et al., 1976). Attempts were made to remove some of the individual components from the SDS-wall of L. buchneri to establish the reattachment site of the subunit protein. Table 1 shows the chemical composition of the wall fractions used as supporting layer for reattachment of the subunit protein. Reattachment was tested by observing negatively stained preparations.

The SDS-wall contained considerable amounts of phosphorus, neutral sugars and glycerol but ribitol was absent. These results indicated that the L. buchneri SDS-wall contained a large amount of glycerol teichoic acid and neutral polysaccharide. When the SDS-wall was further extracted with cold TCA, about $80 \%(w / w)$ of the phosphorus was lost but the amounts of both neutral sugars and amino sugars remained almost unaltered, indicating that most of the teichoic acid had been removed but neutral polysaccharide and peptidoglycan polymers had not been affected by extraction with TCA. Both the SDS-wall and the TCA-wall obtained in 

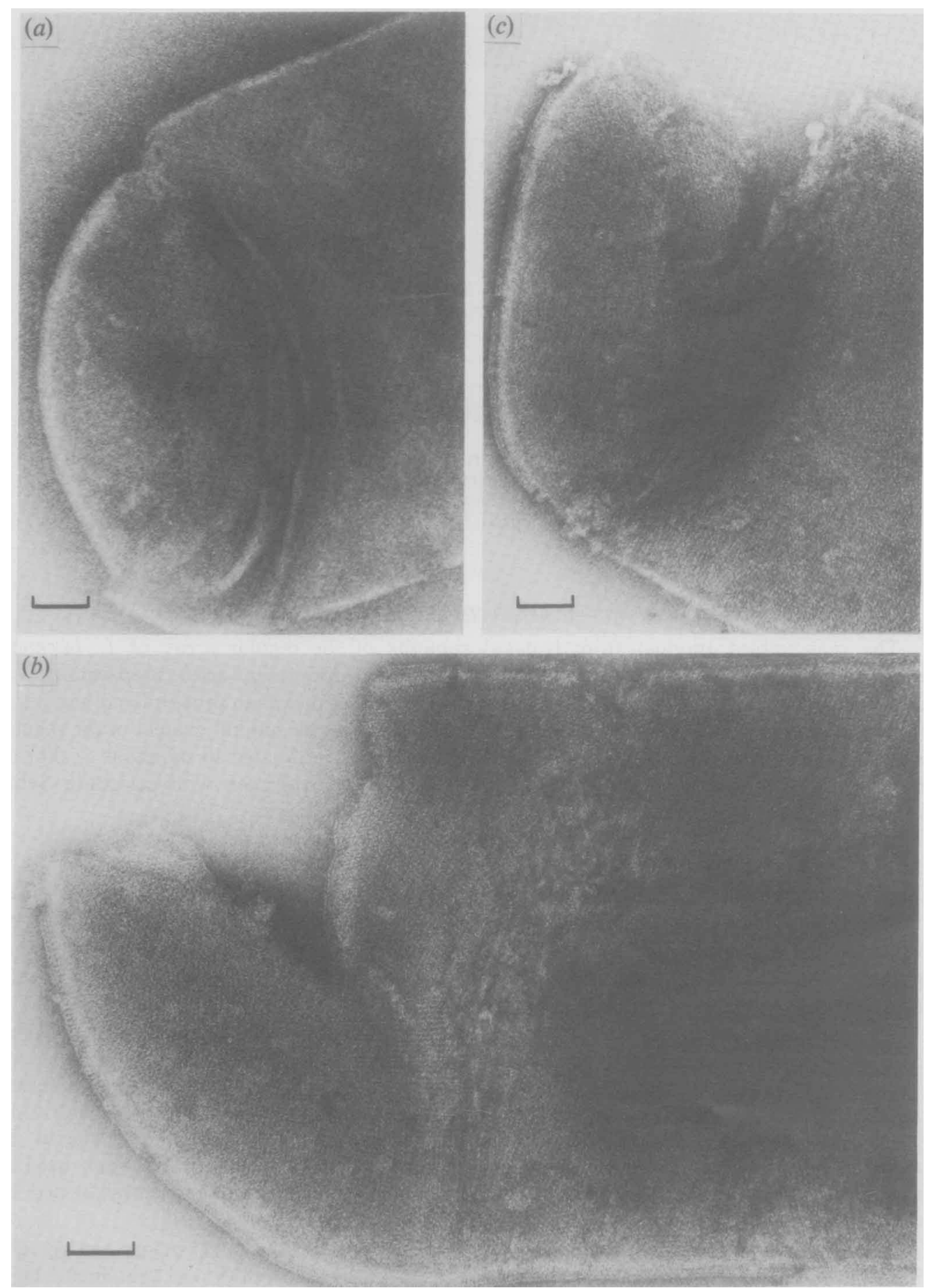

Fig. 4. (a) A GHCl-wall fragment of L. buchneri. The regular array has been completely removed, exposing a smooth underlying layer with a bag-shaped appearance. $(b, c)$ Reattachment of isolated subunits from $L$. buchneri to GHCl-wall $(b)$ or SDS-wall $(c)$. The subunits have reattached to the entire surface of the walls in irregularly oriented patches of pattern. Negatively stained with ammonium molybdate. The bar markers represent $100 \mathrm{~nm}$. 
Table 1. Chemical composition of wall fractions from L. buchneri and reattachment of regularly arranged subunits

Wall fractions were prepared and analysed as described in Methods. Reattachment of subunits was monitored by examining negatively stained preparations.

\begin{tabular}{|c|c|c|c|c|}
\hline \multirow[b]{2}{*}{ Wall fraction } & \multicolumn{3}{|c|}{$\begin{array}{c}\text { Wall component } \\
{\left[\mu \mathrm{g}(\mathrm{mg} \text { dry wt wall fraction })^{-1}\right]}\end{array}$} & \multirow{2}{*}{$\begin{array}{c}\text { Reattachment } \\
\text { of subunits }\end{array}$} \\
\hline & Neutral sugar & Amino sugar & Phosphorus & \\
\hline SDS-wall & 72 & 512 & $66 \cdot 7$ & + \\
\hline TCA-wall & 74 & 550 & 13.4 & + \\
\hline Formamide-wall & $0 \cdot 1$ & 642 & 0.2 & - \\
\hline
\end{tabular}
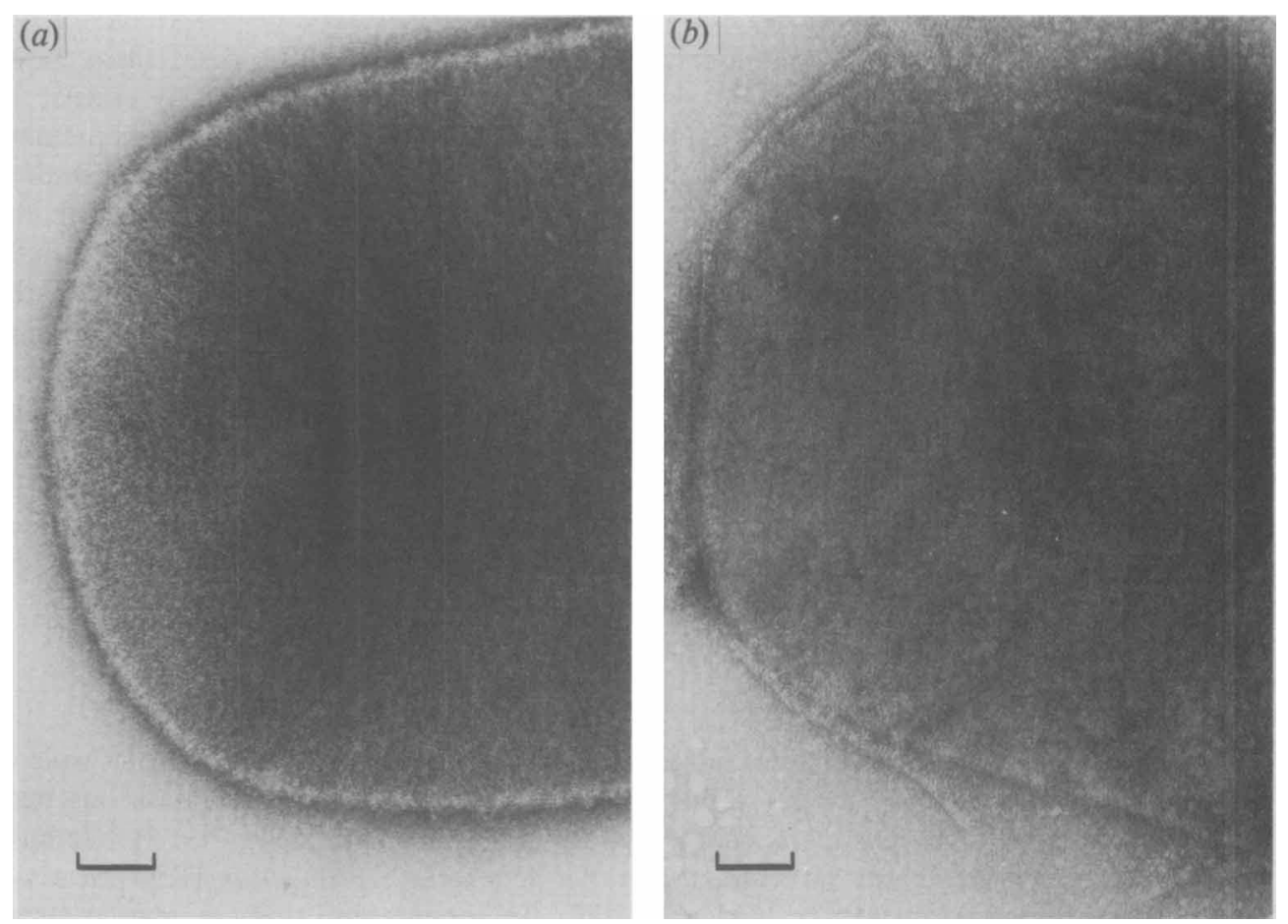

Fig. 5. (a) An HCl-wall fragment of $L$. casei subsp. casei. The wall surface has become slightly rough and fluffy after hydrolysis with $0.5 \mathrm{M}-\mathrm{HCl}$. (b) Reattachment of isolated subunits from $L$. buchneri to $\mathrm{HCl}$-wall of $L$. casei subsp. casei. The subunits are loosely reattached to the edges of the heterologous wall. Negatively stained with ammonium molybdate. The bar markers represent $100 \mathrm{~nm}$.

this way retained the capacity for reattachment of the subunit protein. Treatment of the SDS-wall with hot formamide almost completely removed phosphorus as well as neutral sugars; the resulting formamide-wall contained a peptidoglycan polymer consisting of muramic acid, glucosamine, alanine, glutamic acid, lysine and aspartic acid in a molar ratio of $0.82: 0.86: 1 \cdot 87: 1.00: 0 \cdot 38: 0 \cdot 29$. The subunit protein could not reattach to the formamide-wall. These results suggest that the subunit protein is linked to the neutral polysaccharide moiety of the wall but not to peptidoglycan or teichoic acid.

\section{Reattachment of isolated subunits to heterologous wall fragments}

The specificity of the binding between the subunit protein of $L$. buchneri and wall component(s) was investigated by using wall fragments obtained from L. casei subsp. casei 
Table 2. Chemical composition of wall fractions from L. casei subsp. casei

Wall fractions were prepared and analysed as described in Methods. The values shown are the means of results obtained for two separate samples.

\begin{tabular}{|c|c|c|c|}
\hline \multirow[b]{2}{*}{ Wall fraction } & \multicolumn{3}{|c|}{$\begin{array}{c}\text { Wall component } \\
\mid \mu \mathrm{g}(\mathrm{mg} \text { dry wt wall fraction })^{-1} \mid\end{array}$} \\
\hline & Neutral sugar & Amino sugar & Phosphorus \\
\hline SDS-wall & 311 & 412 & 0.02 \\
\hline HCl-wall & 172 & 640 & ND \\
\hline
\end{tabular}

under the same conditions as for homologous reattachment. The wall of L. casei subsp. casei, which carries no regular arrays (Masuda \& Kawata, 1980), is known to consist of peptidoglycan (L-Lys-D-Asp type: Kandler, 1970) and neutral polysaccharide containing rhamnose, glucose and galactose (Hall \& Knox, 1965) but it lacks teichoic acid (Kandler, 1970). The subunit protein from L. buchneri failed to bind to the SDS-wall or the formamide-wall of $L$. casei subsp. casei. However, when the SDS-wall was treated by mild acid hydrolysis, the appearance of the wall became slightly rough or fluffy (Fig. $5 a$ ) and the subunits were seen to be attached loosely to the HCl-wall fragments (Fig. $5 b$ ). Table 2 shows the chemical composition of the wall fractions from $L$. casei subsp. casei. The SDS-wall was almost free of phosphorus, indicating the absence of teichoic acid. Approximately half the original amount of neutral sugars still remained after mild acid hydrolysis. Knox \& Hall (1965) reported that conditions of mild acid hydrolysis ruptured a covalent linkage between the polysaccharide and mucopeptide components of $L$. casei wall. Our results therefore indicate that the subunit of $L$. buchneri binds to a neutral polysaccharide receptor site embedded within the wall of $L$. casei subsp. casei.

\section{DISCUSSION}

Regular arrays, composed of macromolecular subunits, have been found on the walls of many bacteria (Glauert \& Thornley, 1969), and recently considerable attention has been focused on their structure, chemistry and assembly (Thorne, 1977; Sleytr, 1978). We have observed tetragonal arrays on the wall surface of Lactobacillus fermentum (Kawata et al., 1974) and L. brevis (Masuda \& Kawata, 1979). In the present study a regular array composed of a subunit protein is revealed as a hexagonal pattern on freeze-etched cells of $L$. buchneri. The subunit protein from $L$. buchneri contains no carbohydrate and its apparent molecular weight is about 55000, compared with 51000 for the subunit protein from $L$. brevis (Masuda \& Kawata, 1979). The regularly arranged subunits of thermophilic clostridia (Sleytr \& Thorne, 1976) and Bacillus sphaericus (Hastie \& Brinton, 1979a) are composed of glycoproteins with molecular weights of 140000 and $120000 \pm 3000$, respectively.

The isolated subunits from various bacteria possess the capacity to assemble spontaneously under certain conditions to re-form regular arrays with the same dimensions as those observed in intact walls (Thornley et al., 1974; Sleytr, 1978). The reassembly of isolated subunits from L. buchneri takes place without specific cations or a template. Similar observations were made on the regular arrays from thermophilic clostridia (Sleytr, 1976), $B$. sphaericus (Hastie \& Brinton, 1979a) and L. brevis (Masuda \& Kawata, 1980). These observations suggest that the subunits of these bacteria are linked to each other by hydrogen bonds but not by salt bridges.

Little is known about the specificity of the binding between the regularly arranged subunits and wall components. Based on experiments with isolated components of the outer membrane 
of Acinetobacter sp., Thorne et al. (1975) showed that the regularly arranged surface protein attached to protein in the underlying outer membrane but not to lipid or to lipopolysaccharide. On the other hand, in Spirillum serpens a highly ordered lipid-lipopoly saccharide complex was necessary for the nucleation and assembly of the protein array (Chester \& Murray, 1978). In addition, the ordered hexagonal lattice structure of Escherichia coli was reconstituted on the surface of the lipoprotein-bearing peptidoglycan by mixing the outer membrane protein O-8 and lipopolysaccharide (Yamada \& Mizushima, 1978). Hastie \& Brinton $(1979 b)$ reported that the tetragonal layer protein isolated from $B$. sphaericus could be bound specifically to sacculi (peptidoglycan) of this organism. They suggested that a polymer containing glucosamine and covalently bound to peptidoglycan possibly serves as the binding site for the tetragonal layer protein. From the reconstitution studies reported here we conclude that the neutral polysaccharide moiety in the underlying wall layer is probably responsible for the specific binding of the subunits in Lactobacillus species.

The heterologous reattachment of regularly arranged subunits was first observed in thermophilic clostridia (Sleytr, 1975). Lipopolysaccharide from Pseudomonas aeruginosa could be substituted for that from Spirillum serpens in the reconstitution of a structured layer of outer membrane protein from $S$. serpens (Chester \& Murray, 1978). We also reported that the subunits from $L$. brevis could reattach to the SDS-wall from $L$. fermentum but not to that from L. plantarum or L. casei subsp. casei (Masuda \& Kawata, 1980). On the other hand, binding of the tetragonally arrayed subunits from $B$. sphaericus to purified sacculi was found to be strain specific (Hastie \& Brinton, $1979 \mathrm{~b}$ ). In the present study, although reattachment of the subunits from $L$. buchneri did not take place on the SDS-wall of $L$. casei subsp. casei, binding to the $\mathrm{HCl}$-wall fraction, which retains about half the neutral sugars, did occur. Using mild acid-extraction techniques, Knox \& Hall (1965) showed that the polysaccharide component of the $L$. casei wall was joined through its reducing end group to a phosphate grouping in the mucopeptide. It is suggested that a neutral polysaccharide moiety responsible for binding of the subunit protein of Lactobacillus species is exposed by acid hydrolysis. Teichoic acid is excluded from the role of receptor for the subunit protein since wall teichoic acid was absent in $L$. casei subsp. casei. Further studies will be necessary to elucidate the exact nature of the neutral polysaccharide moiety associated with the subunit protein.

This work was supported in part by a Grant-in-Aid for Scientific Research (no. 337018) from the Ministry of Education, Science and Culture of Japan. We wish to thank Professor Emeritus Yukihiko Mitsui, Department of Ophthalmology, Tokushima University School of Medicine, for allowing us to use the optical diffractometer, and Dr Hideaki Tsuji, Department of Nutrition, Tokushima University School of Medicine, for the amino acid analyses.

\section{REFERENCES}

Allen, R. J. L. (1940). The estimation of phosphorus. Biochemical Journal 34, 858-865.

Chester, I. R. \& Murray, R. G. E. (1978). Protein-lipid-lipopolysaccharide association in the superficial layer of Spirillum serpens cell walls. Journal of Bacteriology' 133, 932-941.

Dubois, M., Gilles, K. A., Hamilton, J. K., Rebers, P. A. \& SMITH, F. (1956). Colorimetric method for determination of sugars and related substances. Analytical Chemistry 28, 350-356.

Efthymiou, C. \& Hansen, P. A. (1962). An antigenic analysis of Lactobacillus acidophilus. Journal of Infectious Diseases 110, 258-267.

Fairbanks, G., Steck, T. L. \& Wallach, D. H. F. (1971). Electrophoretic analysis of the major polypeptides of the human erythrocyte membrane. Biochemistry 10, 2606-2617.
Glauert, A. M. \& Thornley, M. J. (1969). The topography of the bacterial cell wall. Annual Review of Microbiology 23, 159-198.

Hall, E. A. \& KNox, K. W. (1965). Properties of the polysaccharide and mucopeptide components of the cell wall of Lactobacillus casei. Biochemical Journal 96, 310-318.

Hastie, A. T. \& Brinton, C. C., JR (1979a). Isolation, characterization, and in vitro assembly of the tetragonally arrayed layer of Bacillus sphaericus. Journal of Bacteriology 138, 999-1009.

Hastie, A. T. \& Brinton, C. C., JR (1979 b). Specific interaction of the tetragonally arrayed protein layer of Bacillus sphaericus with its peptidoglycan sacculus. Journal of Bacteriology 138, 1010-1021.

KANDLER, O. (1970). Amino acid sequence of the murein and taxonomy of the genera Lactobacillus, 
Bifidobacterium, Leuconostoc and Pediococcus. International Journal of Systematic Bacteriology 20, 491-507.

Kawata, T., Masuda, K., Yoshino, K. \& Fujimoto, M. (1974). Regular array in the cell wall of Lactobacillus fermenti as revealed by freeze-etching and negative staining. Japanese Journal of Microbiology 18, 469-476.

KNox, K. W. \& Hall, E. A. (1965). The linkage between the polysaccharide and mucopeptide components of the cell wall of Lactobacillus casei. Biochemical Journal 96, 302-309.

LAEMMLI, U. K. (1970). Cleavage of structural proteins during the assembly of the head of bacteriophage T4. Nature, London 227, 680-685.

MasudA, K. \& KawatA, T. (1979). Ultrastructure and partial characterization of a regular array in the cell wall of Lactobacillus brevis. Microbiology and Immunology 23, 941-953.

MASUdA, K. \& Kawata, T. (1980). Reassembly of the regularly arranged subunits in the cell wall of Lactobacillus brevis and their reattachment to cell walls. Microbiology and Immunology 24, 299-308.

Matsuno, T. \& Slade, H. D. (1970). Composition and properties of a group A streptococcal teichoic acid. Journal of Bacteriology 102, 747-752.

Rondle, C. J. M. \& Morgan, W. T. J. (1955). The determination of glucosamine and galactosamine. Biochemical Journal 61, 586-589.

Shaw, N. \& BADDILEY, J. (1964). The teichoic acid from the walls of Lactobacillus buchneri N.C.I.B. 8007. Biochemical Journal 93, 317-321.

Shimohashi, H., KodaIRA, S. \& SUEgaRA, N. (1976). Grouping antigens of four Lactobacillus species and their characteristics. Japanese Journal of Microbiology 20, 405-413.

SLEYTR, U. B. (1975). Heterologous reattachment of regular arrays of glycoproteins on bacterial surfaces. Nature, London 257, 400-402.

SLEYTR, U. B. (1976). Self-assembly of the hexagonally and tetragonally arranged subunits of bacterial surface layers and their reattachment to cell walls. Journal of Ultrastructure Research 55, 360-377.

SLEYTR, U. B. (1978). Regular arrays of macromolecules of bacterial cell walls: structure, chemistry, assembly, and function. International Review of Cytology 53, 1-64.

SleYTR, U. B. \& THORNe, K. J. I. (1976). Chemical characterization of the regularly arranged surface layers of Clostridium thermosaccharolyticum and Clostridium thermohydrosulfuricum. Journal of Bacteriology 126, 377-383.

THORNE, K. J. I. (1977). Regularly arranged protein on the surface of Gram-negative bacteria. Biological Reviews 52, 219-234.

ThORNe, K. J. I., ThORnley, M. J., NAISBitT, P. \& GlaueRT, A. M. (1975). The nature of the attachment of a regularly arranged surface protein to the outer membrane of an Acinetobacter sp. Biochimica et biophysica acta 389, 97-116.

Thornley, M. J., Glauert, A. M. \& Sleytr, U. B. (1974). Structure and assembly of bacterial surface layers composed of regular arrays of subunits. Philosophical Transactions of the Royal Society of London, Series B 268, 147-153.

YAMADA, H. \& MIZUSHIMA, S. (1978). Reconstitution of an ordered structure from major outer membrane constituents and the lipoprotein-bearing peptidoglycan sacculus of Escherichia coli. Journal of Bacteriology 135, 1024-1031.

Zacharius, R. M., Zell, T. E., Morrison, J. H. \& WooDLOCK, J. J. (1969). Glycoprotein staining following electrophoresis on acrylamide gels. Analytical Biochemistry 30, 148-152. 